\title{
La privación de libertad en el marco de los derechos humanos
}

\author{
Deprived freedom in the framework of human rights
}

William José Murillo Leiva ${ }^{1}$

\begin{abstract}
RESUMEN
El presente ensayo pretende analizar las condiciones de privación de libertad en relación con los Derechos Humanos y algunos aspectos acerca de estas condiciones en donde se visualiza vulneración a estos. Así, se reflexiona sobre el espacio carcelario como un lugar que atenta contra el respeto por la vida y la dignidad humana. Finalmente, se problematiza sobre algunas de las disposiciones o consideraciones que un gobierno debe tomar en cuenta para lograr un efectivo respeto por los Derechos Humanos de las personas privadas de libertad.

Palabras Clave: Derechos Humanos, población privada de libertad, cárcel, privación de libertad.
\end{abstract}

\begin{abstract}
The present essay intends to analyze the conditions of imprisonment in relation to Human Rights and some aspects about these conditions in which violations of these rights are often visualized. Thus, it reflects on the prison space as a place that attempts against respect for life and human dignity. Finally, discuss on some of the considerations that a government must bear in mind to achieve an effective respect for the Human Rights of persons deprived of freedom.
\end{abstract}

Key Words: Human Rights, deprived of liberty population, social reinsertion, deprivation of liberty.

1 Universidad de Costa Rica. Universidad Estatal a Distancia. Docente en psicología. Costa Rica. Correo electrónico: wilmurilloleiva@gmail.com

Recepción: 12/6/2018 Aceptación: 28/7/2018. 


\section{Introducción}

El presente ensayo analiza las condiciones de privación de libertad en relación con los Derechos Humanos que deben garantizarse a toda persona sin excepción. Cabe destacar que se establece un diálogo con las propuestas de Benito De Castro Cid en su libro Introducción al estudio de los Derechos Humanos (2004), el cual sirve como fundamento conceptual y paradigmático para confrontar la cotidianeidad penitenciaria y para entender la manera plena en que deben disfrutarse tales derechos.

Se hace hincapié en que el escrito parte de una perspectiva crítica que busca problematizar acerca de la vulneración de derechos humanos a la población privada de libertad e interpela a una institución carcelaria en dónde prevalece el castigo y deterioro físico y psicológico de las personas privadas de libertad.

La pregunta que impulsa a este ensayo es básica: ¿es posible construir el respeto por la vida y dignidad humana y los Derechos Humanos en un espacio que los invisibiliza o los deteriora? La respuesta se hace evidente, vamos a comenzar a argumentarla.

\section{Derechos humanos y la privación de libertad}

La cárcel significa, para muchas personas y sectores de la población, inclusive académicos y profesionales, un espacio destinado para el castigo y, por ende, se le atribuye a éste la autonomía y la capacidad de ejecutarlo, sobre la población reclusa, de la manera que considere. Ya lo dijo Foucault -y a profundidad-

\footnotetext{
La prisión, la región más sombría dentro del aparato judicial, es el lugar donde el poder de castigar, que ya no se atreve a actuar a rostro descubierto, organiza silenciosamente un campo de objetividad donde el castigo podrá funcionar en pleno día como terapéutica, y la sentencia inscribirse entre los discursos del saber (Foucault, 2008, p. 296).
}

A continuación destaco y reflexiono acerca -y solo de algunos- de los derechos humanos que son violentados en este espacio de castigo legitimado por el poder, la cárcel. Considero que no está demás seguir puntualizando en esto aunque se hayan escrito multiplicidad de letras al respecto ya.

En este sentido, comienzo destacando a la integridad física. La integridad física de los privados y privadas de libertad es uno de los aspectos más vulnerados y no pareciera 
reconocerse como un derecho inherente a dichas personas; por su condición y como resultado de procesos de estigmatización social y “deshumanización”. En tanto, pareciera que, una vez que son dictadas las respectivas y, vale decir, muy variadas sentencias de la población privada de libertad, ésta se constituye como un nuevo grupo humano con características propias y disímiles al resto de los grupos sociales.

Con respecto a los derechos que protegen la integridad física y moral dice De Castro (2004): "Los numerosos derechos humanos que cumplen la función primordial de contribuir a la conservación y desarrollo plenario de la vida de los hombres actúan en un doble plano: el inmediatamente biológico y el fundamentalmente psíquico-social o moral” (p. 250).

En este sentido, en la cuestión penitenciaria, con relación al desarrollo pleno de la vida y, en lo respectivo al plano inmediatamente biológico; se podría decir que al no existir pena de muerte en nuestro país, Costa Rica, es posible entender o visualizar un estado que garantiza la vida y por ende, el derecho a la integridad física pero: ¿qué pasa dentro del encierro? ¿se pone en riesgo la vida? ¿se violenta la integridad física de los internos? Es evidente que la respuesta es sí.

En las condiciones usuales de encierro en nuestro país y en general en el contexto latinoamericano, el hacinamiento, las agresiones y la violencia son normales y peor aún, normalizadas, por ende, la vulnerabilización al derecho es evidente, pese a que la responsabilidad de los ordenamientos jurídicos es innegable.

La vida es ciertamente un hecho, pero ese hecho se constituye de modo automático en contenido de un derecho de conservación y de defensa, que corresponde a todos los individuos humanos vivientes y que ha de ser objeto de protección por parte de los ordenamientos jurídicos (De Castro, 2004, p. 258).

No quiere decir lo anterior que no sea importante reconocer el valor que tiene, para el sistema judicial y penitenciario nacional el no ejercicio de la pena de muerte; debe mantenerse y recalcase su importancia y su valía para que, ante ciertos discursos retrógrados, punitivos o populistas, parezca una buena opción por instaurar, porque "desde el punto de vista teórico, parece claro que, por simple coherencia lógica, las concepciones que proclaman la dignidad suprema del ser humano y el derecho general a la vida deberían desembocar en la abolición de la pena de muerte" (De Castro, 2004, p. 263). Así, no se trata de invisibilizar este logro, pero sí de ampliar sus implicaciones y de proponer que el derecho a la integridad física, inclusive desde la referencia estrictamente biológica, no se limita a la inexistencia de 
la pena de muerte. Se trata de visualizar que en los centros penitenciarios la atención a la salud es deficiente, que las condiciones higiénicas son inmensamente problemáticas, que el manejo de los alimentos es inadecuado, que la dinámica interna de narcotráfico y la violencia inherente a esta, entre otras muchas cosas, son afrentas evidentes al derecho humano a la integridad física.

El derecho a la integridad física pone a cuestión y a reflexión la vida misma, su valor y su significado. Ciertos grupos de personas marginalizadas en el sistema socioeconómico y político actual, dejan de ser valiosas y dignas de humanidad y por ende su vida es menos importante, su vida es una vida desnuda (Aganbem, 2006). Aquí, el ejemplo no solo se refiere a la población privada de libertad, sino también a otros grupos marginalizados y que en este sistema inclusive son ahora criminalizados; por ejemplo: personas refugiadas y migrantes, entre muchos otros. Ante esto, resalta la obligación que debe tener el Estado de protección y de resguardo de la vida. Esto es la dimensión positiva que destaca De Castro (2004), la obligación que tiene la organización social a la que pertenece cada individuo de proteger su vida contra cualquier ataque. ¿Asume el Estado esta responsabilidad de la misma manera para todos los grupos sociales? Parece que no lo hace, aún y cuando "Este derecho ha de ser considerado como radicalmente inderogable, en el sentido de que no puede ser suprimido o suspendido legítimamente bajo ninguna circunstancia o condición” (De Castro Cid, 2004, p. 260). Se entiende que cuando dice "bajo ninguna circunstancia o condición”, se incluye o, se debería incluir a la población privada de libertad o a cualquier otro grupo minoritario y vulnerable.

Ahora bien, ¿qué pasa con respecto a la integridad psíquica y moral? Me parece que la problemática es mayor. De sobra es entendido por la ciencia y la teoría que la cárcel, y en general la institución total, genera enorme afectación a nivel psicológico en tanto, y entre muchas cosas, favorece una regresión a etapas infantiles y limita el desarrollo de la autonomía y el yo personal. Entonces, el derecho se ve violentado en ambos ámbitos, en torno a la vida y su plano biológico y en torno a la integridad psíquica y moral.

Junto al valor radical de la vida y la salud corporal o biológica, está el valor a la vida y la integridad moral, como una realidad totalmente inseparable de la primera, por cuánto el hombre es en sí mismo una irrompible unidad, coherente y dinámica, aunque de naturaleza bidimensional. (De Castro, 2004, p.251). 
En este aspecto la cuestión carcelaria tiene enormes implicaciones y plantea a la administración y gestión de la misma significativos retos. Podemos aquí destacar la cuestión integral del "yo" y su debilitamiento en el encierro, la afectación producto de la monotonía del centro penitenciario, la angustia emocional y la ansiedad que genera la adaptación a la institución. Además, se puede profundizar en otras cuestiones, por ejemplo: ¿qué pasa con los grupos de minorías dentro de los centros penitenciarios? ¿se protege en las cárceles el derecho a la identidad de género? ¿a la preferencia sexual? ¿se adecuan espacios de acuerdo a las especificidades de la población indígena? ¿se asegura el respeto y la dignidad de las personas migrantes? La respuesta, en la mayoría de los casos es: no. Está claro que todos estos aspectos, cuando son atendidos con prontitud, interés y acciones para su defensa y adecuado manejo están relacionados y potencian el desarrollo de un yo integral y por ende de una cotidianeidad coherente con el disfrute del derecho a la integridad psíquica y moral e inclusive fìsica; aún así, las respuestas a las interrogantes planteadas siguen siendo, casi siempre, no. Hace falta mucho por asegurar con respecto a la integridad psìquica y moral de la población penitenciaria.

El reto entonces es enorme: incluye a las mayorías y a las minorías para que, producto de la dinámica penitenciaria, no vean violentada ni agredida su dignidad, su humanidad. En la cárcel los grupos minoritarios con necesidades específicas y condiciones únicas deben ser entendidos, analizados y abordados de acuerdo a sus especificidades, la cárcel no debe agravar la estigmatización o discriminación de estos grupos, al contrario, debe respetar la identidad que reconocen inherente a sí mismos, respetar su integridad psíquica y moral.

Ahora bien, mucho se puede decir, también, con respecto al derecho a la intimidad en el contexto de la privación de la libertad. El hacinamiento, la dinámica penitenciaria e inclusive el mismo diseño de las cárceles claramente violenta este derecho que no debería verse quebrantado ante una pena que limita la libertad de tránsito. Resulta muy interesante la relación de este derecho con el derecho a lo privado, que, en condiciones de encierro, es prácticamente algo inexistente. Así, dice De Castro: "El reconocimiento del derecho a la inviolabilidad de la vida privada supone, pues, la aceptación de que cada sujeto tiene pleno dominio sobre una zona de su propia vida y actividad (...)” (2004, p. 274). 
En la cárcel, el espacio privado intenta delimitarse con sábanas y colchones, -casi siempre comprados o alquilados a algún otro interno o interna- $\mathrm{y}$, en el mejor de los casos. Espacio que de todas maneras es violentado por la "requisa", el hacinamiento en general y las disposiciones de traslado o cualquier otra propia a la dinámica carcelaria. No se trata entonces de seguir pensando que esto por ser cárcel es legítimo porque no es así, o al menos, no debería serlo. La intimidad y lo privado se viola en el golpe aplastante del panóptico, en los cuerpos hacinados que se amontonan uno encima o a la par del otro, en las cartas y las fotos familiares que se pierden en requisas o traslados apresurados.

Además, es muy interesante relacionar lo mencionado con la autonomía, quizás una de las cuestiones más violentadas en el encierro y de mayor impacto a nivel psicológico. En relación a esto, dice De Castro: "así que la inviolabilidad de la vida privada actúa como un muro que protege aquellos aspectos de la vida que la mayoría de los individuos considera elementos importantes de un ámbito de autonomía que debe quedar sustraído al conocimiento de los otros miembros del grupo social" (2004, p. 274). En el caso de los privados de libertad no existe dicha autonomía, no hay capacidad de decidir sobre procesos básicos y trascendentales como lo que es público y lo que es privado y claramente la posibilidades de sustraer lo propio de la mirada del grupo social es imposible.

Está claro que la institución penitenciaria implica cuestiones y limitaciones específicas, pero, como he mencionado, esto no debe oponerse a una crítica en torno a la violación de derechos y por ende a la posibilidad de cambios y mejores condiciones en coherencia con derechos humanos básicos.

En relación a lo anterior, con respecto al derecho de la libertad, De Castro (2004) destaca a la libertad espiritual y física como elemento trascendental para el ser humano. En lo penitenciario se puede visualizar una doble afectación. Por un lado, priva la libertad física y por otro limita, en base a la monotonía, las condiciones indignas y otros factores, la autonomía espiritual y psíquica. En los centros penitenciarios, la dinámica es tan opresiva y poco estimuladora que los seres humanos ahí internos ven afectada su autonomía, limitado e invadido su yo y condicionado su desarrollo personal y espiritual.

Así, resulta muy interesante analizar la cuestión de los derechos humanos en torno a la privación de la privación de la libertad porque, para algunos grupos sociales, estos seres 
humanos no son tan importantes o dignos a la hora de exigir estos derechos, por ejemplo: el derecho a la educación. "Resulta legítima esa imposición del deber de escolarización (esa representación del derecho a la educación como derecho-deber) en tanto en cuanto constituye un instrumento indispensable para la realización de la libertad individual (...)”. (De Castro, 2004, p. 302). Y en este sentido, dice Scarfó, (2002) "Es la educación en general, y en especial en los establecimientos penales, la que actúa como resguardo de la condición de ser humano para aquellas personas que alguna vez han delinquido" (p. 292). Es decir, la privación de la libertad no involucra que se "degraden" otro tipo de derechos ni su exigibilidad. Así, si se habla del derecho a la educación, se debe presuponer que se incluye en éste a la población privada de libertad. La cuestión es que esto no se entiende siempre así.

Acerca del derecho a la educación en centros penitenciarios creo que es una de las mejores oportunidades para la potenciación del ser humano. Pero ¿es esto valorado y tomado con importancia por la sociedad? ¿La academia? ¿La política? Aquí cobra gran importancia lo relacionado a las condiciones, no solo para el derecho a la educación si no para los derechos en general. Pareciera que con el hecho de que existan ofertas educativas se cumple con garantizarlo, pero, este derecho abarca una serie de condiciones imprescindibles para que su realización sea justa y coherente con el desarrollo de los aprendizajes. En relación a esto, dice De Castro

La acción de los poderes públicos a este respecto no debe limitarse a la simple prestación del servicio educativo, ni siquiera sólo a la garantía de la gratuidad en su prestación. (...). Es necesario que los individuos dispongan de tiempo suficiente y posibilidades reales para acceder a la educación en las condiciones que permitan obtener el debido provecho de la misma (2004, p. 303).

Y lo anterior con respecto al derecho a la educación, pero se pueden citar muchos otros derechos que no se cumplen con esfuerzos limitados o "maquillados" en las cárceles, por ejemplo, el derecho a la salud o al trabajo. Inclusive De Castro destaca, cuando se refiere a la medidas económicas y sociales necesarias para la garantización de los derechos humanos, que:

Por citar algunas cuestiones de las obligaciones del Estado diremos que éste debe garantizar las condiciones para que todos los ciudadanos tengan acceso a un nivel de vida digna, a una alimentación adecuada, asegurar el acceso a un hogar, (vivienda que reúna las condiciones higiénicas indispensables), al empleo y aun remuneración justa, a la protección de la salud, y unas condiciones sanitarias básicas (...). (2004, p. 340).

¿La salud en la cárcel se asegura de manera integral y adecuada? ¿el trabajo? ¿se propone, por ejemplo, el desarrollo laboral de las mujeres con ocupaciones y profesiones que 
sean reaccionarias a lo planteado por el patriarcado y la heteronormatividad? Hace falta mucho en torno a los Derechos Humanos y su defensa en los centros penitenciarios.

\section{Condiciones para la realización de los Derechos humanos}

Ahora quisiera destacar un par más de aspectos, principalmente relacionados con las condiciones para la realización de los Derechos Humanos.

Primero, me resulta interesante problematizar acerca de si podemos entender a las condiciones penitenciarias latinoamericanas, caracterizadas por el hacinamiento, la violencia y la afectación a la dignidad humana como una emergencia humanitaria o una situación límite y que pueda convocar al derecho a la asistencia humanitaria. ¿Podemos hacerlo? ¿facilitaría intervenciones necesarias y especiales? quizás sí.

De Castro (2004) menciona que “(...) toda persona, comunidad o Estado, tiene derecho a ser ayudado por los demás en caso de encontrarse en una situación límite y que no pueda enfrentarse efectivamente con sus propios recursos" (p. 322). Es muy interesante que el autor destaca que esto debe responder a una cuestión coyuntural para no confundirla con el derecho al desarrollo y por ende creo que no resulta tan inadecuado reflexionar acerca de lo penitenciario como una emergencia humanitaria y coyuntural.

Ante la incapacidad y progresivos errores en el manejo de lo criminal y lo penitenciario, las cárceles latinoamericanas están colapsadas por el hacinamiento y esto, entre otras múltiples cuestiones, ha generado situaciones de extrema violencia, reflejado en mayor o menor medida en todos los países. Tal vez es momento de atender la situación con coordinaciones interregionales e internacionales y con el fin de enfrentar la situación desde las múltiples variables que la atraviesan y comprenden; en función de garantizar la defensa de los Derechos Humanos de las poblaciones internas, sus familias y en general de la sociedad completa. La cárcel, como institución social y de gobierno, nos representa a todos y todas.

Además, y siempre relacionado con lo anterior, me parece importante referirme a las condiciones políticas necesarias para la garantía de los Derechos Humanos, dice De Castro (2004): “(...) para que realmente sea posible el ejercicio de los derechos humanos se requiere 
en primer lugar la existencia de: a) un Estado de Derecho; b) un Estado Democrático y c) un Estado Social" (p. 332). Esto involucra multiplicidad de cuestiones como: el principio de legalidad, pluralismo político y descentralización del Poder, entre otras varias.

De acuerdo a lo anterior, está claro que el respeto a los derechos humanos en el contexto penitenciario está íntimamente determinado por el contexto político y las condiciones que éste garantice, esto a través de acciones concretas y con un fundamento ideológico y epistemológico bien definido. Por ejemplo, si bien la tarea y los retos y necesidades son grandes, este gobierno (2014-2018), a través del Ministerio de Justicia, ha demostrado una intención traducida en acciones para promover un sistema penitenciario más coherente con la dignidad humana y alejada de populismos y administraciones clientelistas de lo punitivo y penitenciario. Este Ministerio, por ejemplo y entre otras varias cuestiones, clausuró recién en el año 2017 un ámbito de "La Reforma" que no podía estar más alejado de lo "reahabilitante" y de lo coherente con la dignidad humana: el antiguo ámbito de máxima seguridad que no era más que un calabozo dispuesto a mutilar las condiciones esenciales para el desarrollo de la salud mental, entre otras muchas cosas más.

Así, la historia penitenciaria demuestra que los cambios se pueden dar pero que no es algo constante, por ende, siempre es una cuestión política y de voluntad.

Continuando con las condiciones políticas, se destaca la importancia de la democratización política para el establecimiento de los Derechos Humanos.

Frente al modelo de la comunicación social sólo caben sociedades autoritarias o totalitarias, montadas sobre el miedo y la desconfianza y donde la dialéctica amigo-enemigo es la clave de la vida política. En efecto, donde no hay comunicación se propicia el enfrentamiento y el único motor político de las sociedades enfrentadas será el odio (De Castro, 2004, p. 335).

Destaco lo anterior porque me parece que refleja de manera muy explícita cómo es que funcionamos en sociedad, cómo funciona la criminología mediática cuando no hay condiciones políticas de apertura y democratización. Refleja lo anterior cómo es que establecemos diferenciaciones y distancias entre unos y otros. Aquí, por supuesto, se puede referir a las personas en conflicto con la ley, las poblaciones privadas de libertad y en general las poblaciones marginalizadas, a la cuales usualmente se les asigna una categoría de "enemigos", de "anormales", de "distintos"; incrementando esto las diferencias, la desigualdad, el odio y de manera general, la imposibilidad del disfrute de los Derechos Humanos. 
Rey (2011) se refiere también a lo anterior y destaca que "ante el miedo y por incrementar la seguridad, la ciudadanía parece dispuesta a asumir el recorte de libertades y no sólo de estas, sino también de los derechos sociales" (p. 142). Inclusive destaca a la prisión mencionando que ante esta sensación de inseguridad y miedo generalizado se profundiza en el Derecho Penal y "la prisión se convierte en el principal instrumento de prevención, ya no es una institución orientada a la resocialización sino simplemente a impedir que el riesgo se materialice" (Rey, 2011, p. 147). Aún y cuando la resocialización es, en mi perspectiva, siempre ilógica con respecto a la función de la cárcel y muchas veces incoherente en relación con lo criminológico, está claro que esta institución poco a poco y cada vez más, se estructura pensando en impedir el "riesgo" y promover el castigo por sobre algunas otras intenciones "resocializadoras".

\section{Conclusiones}

Las posiciones planteadas en este escrito no están relacionadas con una defensa de la impunidad o de invisibilización de los procesos de sufrimiento de las víctimas. No hay que confundir una aproximación hacia lo penitenciario en busca de condiciones coherentes con la dignidad humana con un manejo que busque la impunidad, es precisamente todo lo contrario. Es más, la clave es, no solo el aseguramiento de condiciones coherentes con la dignidad humana, sino que se replanteen y construyan modelos de trabajo a lo interno de las cárceles que posibiliten una intervención de los factores de afectación mencionados, entre otros y por ende impacten en beneficio de la sociedad en general. La promoción debe ser de la salud mental, de oportunidades, de crecimiento, de resignificación y de mejores vidas posibles.

Si bien la cárcel, indiferentemente de sus condiciones, siempre es cárcel, siempre es institución total en tanto le sea inhabilitada al individuo interno su capacidad de decisión con respecto a cuándo salir del lugar y por ende siempre va a tener una afectación en tanto el interno experimenta un proceso de regresión hacia una etapa superada en el proceso de la vida y vuelve a depender de muchos actores por sobre y ajenos a él; las condiciones, la dinámica y modelo de trabajo de la misma, van a ser determinantes a la hora de aminorar o aumentar la afectación que ésta involucra. 
La monotonía, la traslación de la pena a los familiares, la perdida de la intimidad y, en muchas ocasiones y eventos, la pérdida de la decisión con respecto a cómo y cuándo se hacen las cosas son parte de los efectos psicosociales de la institución carcelaria y estos pueden verse desarrollados en mayor o menor medida en función de condiciones institucionales coherentes con la dignidad humana y los derechos humanos y adecuados modelos de trabajo.

Es importante destacar que la cárcel es un reflejo de la sociedad en la que se encuentra, por lo tanto nos habla de un sistema político que la sostiene. Este sistema político debe interrogarse críticamente a sí mismo y estar en constante estado de reconstrucción para lograr el mejoramiento de las condiciones de vida humana y garantizar el respeto por los Derechos Humanos.

Finalmente, y a manera de máxima, los derechos humanos no tienen una categoría o una "generación" diferenciada para la población en conflicto con la ley y/o privada de libertad, por lo tanto, el respeto y la garantía por los Derechos Humanos deben fomentarse y evidenciarse en las instituciones carcelarias para lograr el fortalecimiento del lazo social y del respeto por la vida y dignidad propia y ajena.

\section{Referencias}

Aganbem, G. (2006) Homo Sacer: El poder soberano y la nuda vida. 1a. ed. Valencia: Pretextos.

De Castro Cid, B. (2004). Introducción al estudio de los Derechos Humanos. Madrid, España: Universitas S.A.

Foucault, M. (2008). Vigilar y Castigar. Buenos Aires, Argentina: Siglo XXI Editores.

Rey, J., L. (2011). El discurso de los derechos: una introducción a los derechos humanos. Madrid, España: Universidad Pontificia Comillas.

Scarfó (2002). El derecho a la educación en las cárceles como garantía de la educación en derechos humanos. Revista IIDH. $N^{\circ} 36.291-324$. 